Supporting Information for Publication

\title{
Stable Photoelectrochemical Water Splitting using p-n GaN Junction Decorated with Nickel Oxides as Photoanodes
}

Chi Wing Lee', Feng-Wu Lin ${ }^{1,2}$ Po-Hsun Liao', Ming-Lun Lee ${ }^{2 *}$ and Jinn-Kong Sheul*

1 National Cheng Kung University, Department of Photonics, Tainan City 70101,

Taiwan.

2 Southern Taiwan University of Science and Technology, Department of Electro-

Optical Engineering, Tainan City 71005, Taiwan.

Email: jksheu@,ncku.edu.tw; minglun@stust.edu.tw 
Table S1: The XPS integrated area of $\mathrm{Ni}^{2+}$ and $\mathrm{Ni}^{3+}$.

\begin{tabular}{|c|c|c|}
\hline & Area of Ni3+ & Area of Ni2+ \\
\hline Before PEC & 7249.3 & 1850.1 \\
\hline Area(\%) & $79.7 \%$ & $20.3 \%$ \\
\hline After PEC & 902.1 & $/$ \\
\hline Area(\%) & $100.0 \%$ & $/$ \\
\hline
\end{tabular}

Table S2: The $\mathrm{pH}$ value of the electrolytes before and after the PEC reactions.

\begin{tabular}{|c|c|c|c|c|}
\hline & \multicolumn{2}{|c|}{ WE side } & \multicolumn{2}{c|}{ CE side } \\
\hline Photoanodes & Before & After & Before & After \\
\hline n-GaN & 6 & 6 & 6 & 6 \\
\hline pn-GaN & 6 & 5.5 & 6 & 6.3 \\
\hline NiOx/pn-GaN & 6 & 4.7 & 6 & 6.8 \\
\hline
\end{tabular}

Table S3. Measured OCP values of the GaN photoanodes before the stability test.

\begin{tabular}{|c|c|c|c|}
\hline Photoanodes & $\begin{array}{c}\mathbf{O C P} \text { at } \\
\text { dark } \\
\left(\mathbf{O C P}_{\text {dark }}\right)\end{array}$ & $\begin{array}{c}\mathbf{O C P} \text { under } \\
\text { illumination } \\
\left(\mathbf{O C P}_{\text {light }}\right)\end{array}$ & $\begin{array}{c}\left|\mathbf{O C P}_{\text {light }}-\mathbf{O C P}_{\text {dark }}\right| \\
\left.\mathbf{( V}_{\mathbf{p h}}\right)\end{array}$ \\
\hline $\mathrm{n}-\mathrm{GaN}$ & $0.51 \mathrm{~V}_{\mathrm{RHE}}$ & $0.12 \mathrm{~V}_{\mathrm{RHE}}$ & $0.39 \mathrm{~V}_{\mathrm{RHE}}$ \\
\hline $\mathrm{pn}-\mathrm{GaN}$ & $0.24 \mathrm{~V}_{\mathrm{RHE}}$ & $-0.31 \mathrm{~V}_{\mathrm{RHE}}$ & $0.55 \mathrm{~V}_{\mathrm{RHE}}$ \\
\hline $\mathrm{NiOx} / \mathrm{pn}-\mathrm{GaN}$ & $0.73 \mathrm{~V}_{\mathrm{RHE}}$ & $-0.41 \mathrm{~V}_{\mathrm{RHE}}$ & $1.14 \mathrm{~V}_{\mathrm{RHE}}$ \\
\hline
\end{tabular}


Supporting Information Section S1:
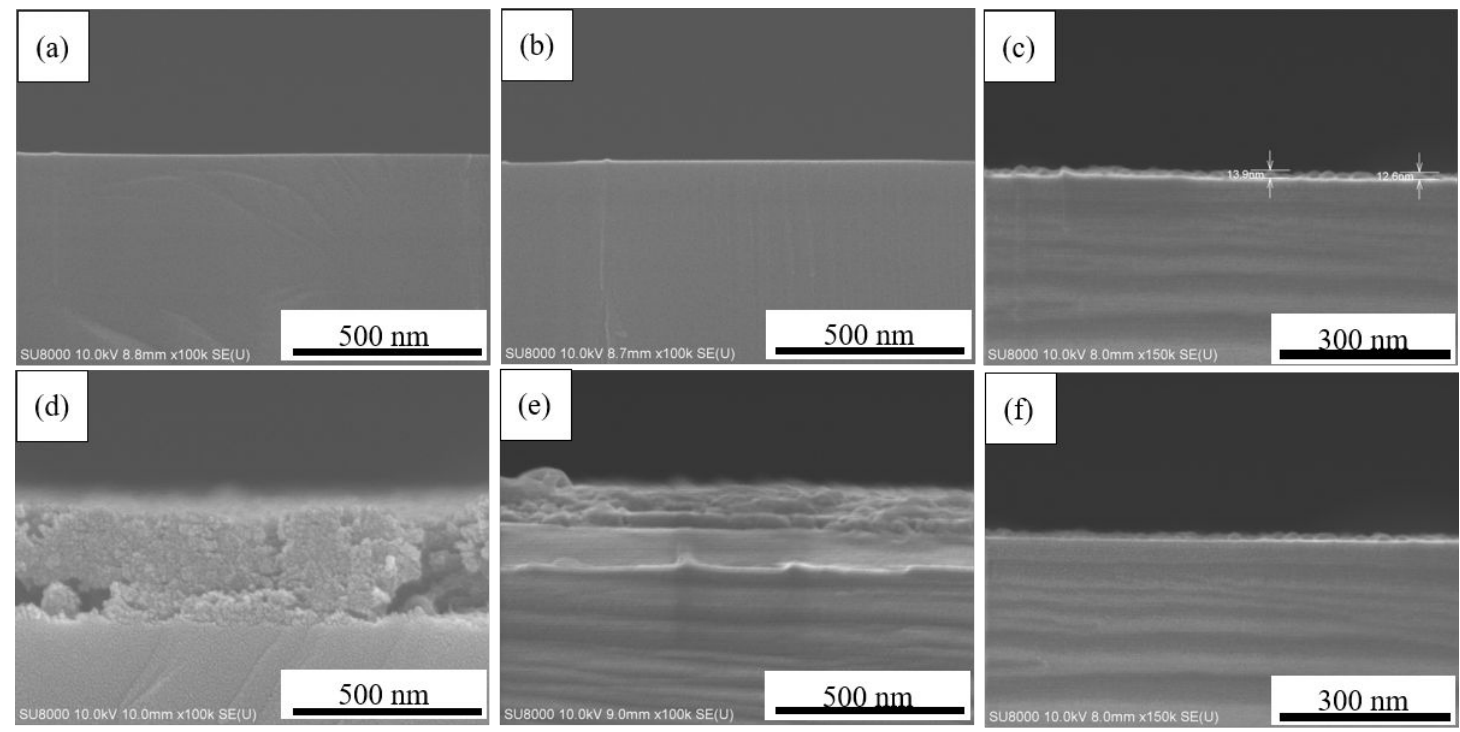

Figure S1. Cross-section SEM images of the photoanodes. (a) n-GaN, (b) pn-GaN, (c) $\mathrm{NiOx} / \mathrm{pn}-\mathrm{GaN}$ before the PEC reactions, and (d) n-GaN, (e) pn-GaN, (f) NiOx/pnGaN after the PEC reactions. 
Supporting Information Section S2:

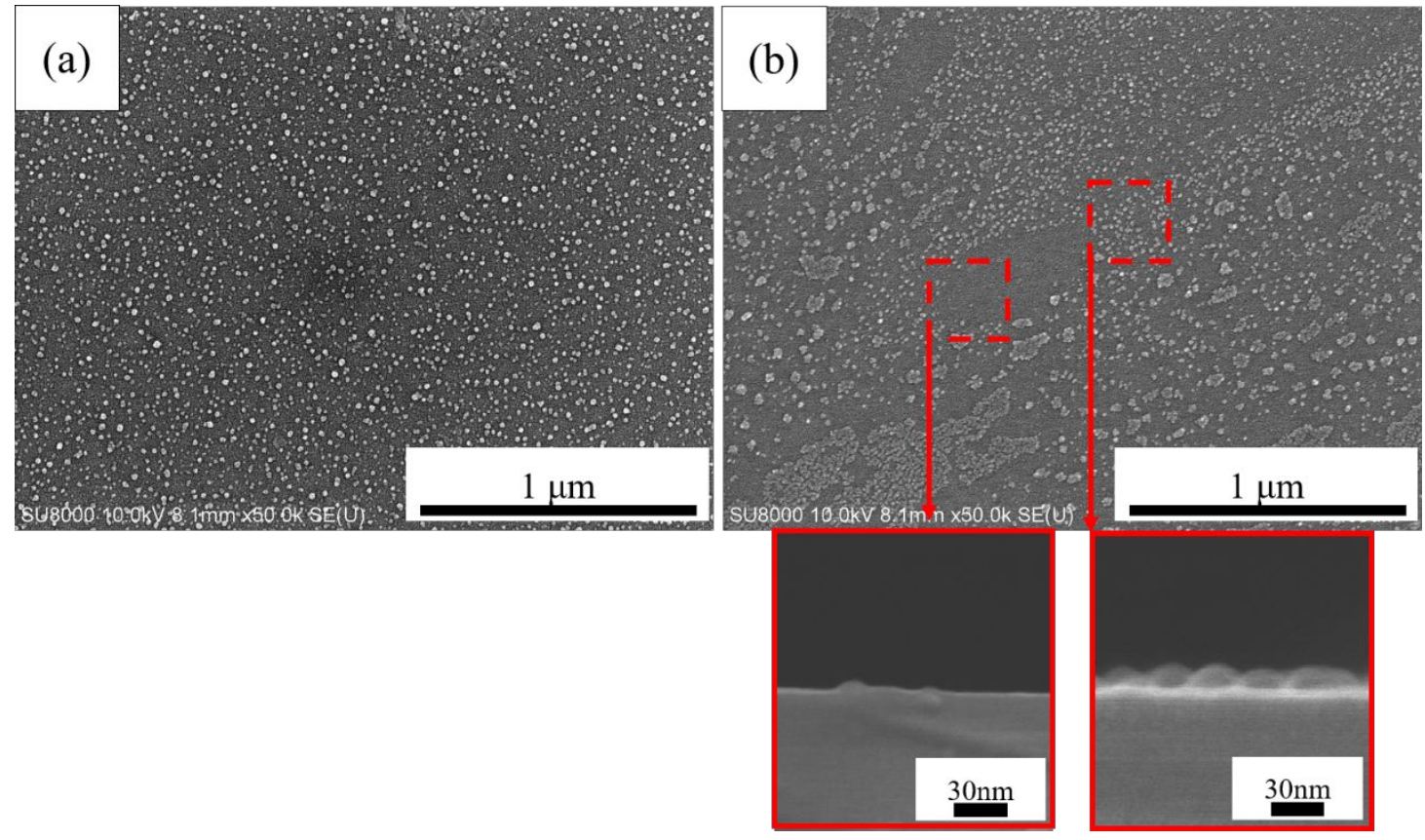

Figure S2. Typical top-view SEM images of the NiOx/pn-GaN photoanodes (a) before and (b) after the PEC reactions. The insets of figure S2b show the cross-section view of SEM taken from the different areas on the NiOx/pn-GaN photoanodes after the PEC reaction. This result indicates that a part of $\mathrm{NiO}$ nanoparticles is shed from the GaN film. 


\section{Supporting Information Section S3:}

The carrier concentration of the $\mathrm{n}-\mathrm{GaN}$ and the $\mathrm{p}-\mathrm{GaN}$ layer were set to $1 \times 10^{19}$ and $3 \times 10^{17}$, respectively. The electron affinity and the valence band edge of $\mathrm{GaN}$ are about $4.1 \mathrm{eV}\left(-0.4 \mathrm{~V}_{\mathrm{RHE}}\right)$ and $7.5 \mathrm{eV}\left(+3 \mathrm{~V}_{\mathrm{RHE}}\right)$, respectively. The redox couple $\left(\mathrm{O}_{2} / \mathrm{H}_{2} \mathrm{O}\right)$ with potential (1.23 $\left.\mathrm{V}_{\mathrm{RHE}}\right)$ was used in the simulation program.

Figure S3 shows that the depletion region increased with the thickness of the surface p$\mathrm{GaN}$ layer. Due to the large difference in the carrier concentration between the $\mathrm{p}-\mathrm{GaN}$ and $\mathrm{n}-\mathrm{GaN}$ layer, the depletion region is formed at the surface $\mathrm{p}-\mathrm{GaN}$ layer. Compared to case (i) $\mathrm{p}=0 \mathrm{~nm}$ (which is equivalent to the bare $\mathrm{n}-\mathrm{GaN}$ ), the band bending profiles of the cases (ii) $\mathrm{p}=30 \mathrm{~nm}$ and (iii) $\mathrm{p}=70 \mathrm{~nm}$ indicate that the $\mathrm{p}-\mathrm{GaN}$ cap layer is beneficial for charge separation. In the case (iv) $p=150 \mathrm{~nm}$, the thickness of the $p-G a N$ layer is too thick; The photogenerated holes will accumulate in the depletion region, thereby increasing the recombination events of the photocarriers. Our simulation results show that the optimum thickness of the p-GaN layer is around $70 \mathrm{~nm}$, which can provide an appropriate depletion width for the charge separation.

The band simulation program (1D-DDCC), developed by Prof. Yuh-Renn Wu from National Taiwan University (NTU), is free and available http://yrwu-wk.ee.ntu.edu.tw/.

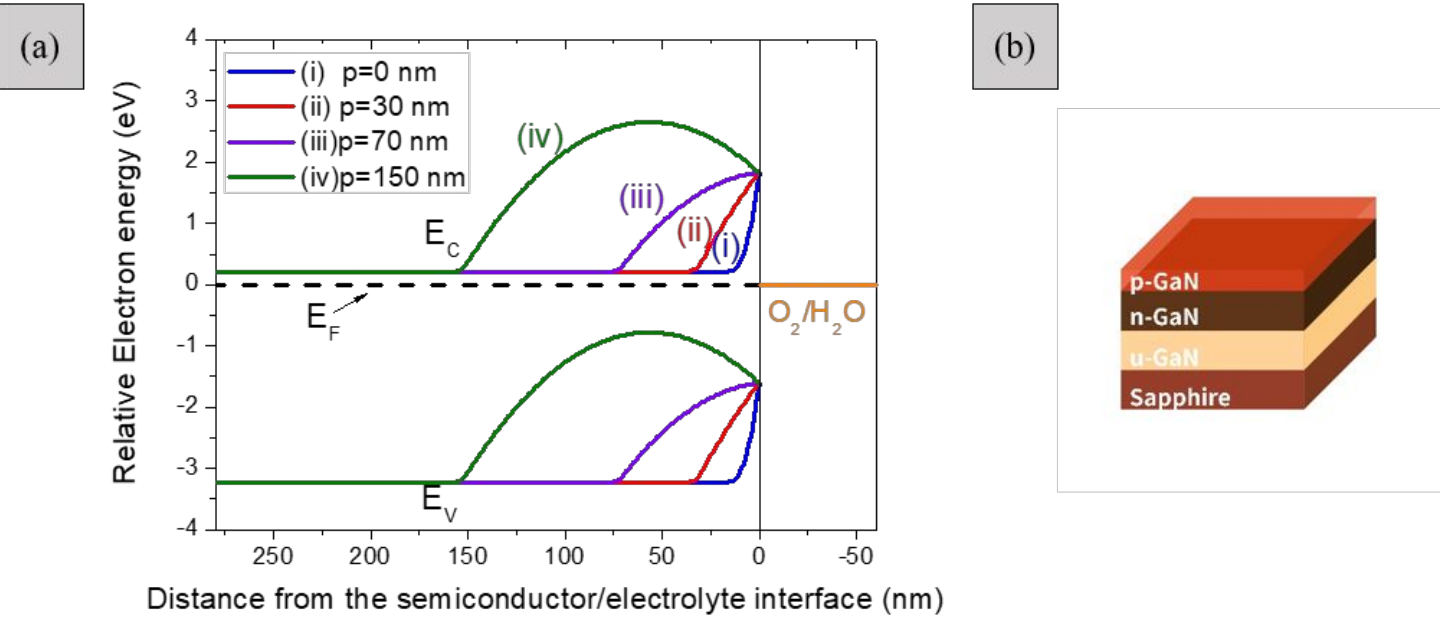

Figure S3. (a) The simulation band structure of the pn-GaN with different $p-G a N$ thickness. (b) The schematic diagram of the pn-GaN wafers. 


\section{Supporting Information Section S4:}

The open-circuit potential (OCP) analysis was performed using a three-electrode configuration. Under the open-circuit condition and illumination, the band bending of a particular photoelectrode is close to its flat-band (i.e., The $\mathrm{OCP}_{\text {light }}$ value approximates the flat-band potential).

Moreover, the difference between the OCP values under the light on and light off conditions represents photoelectrode's photovoltage ( $\mathrm{Vph}$ ). The photoanodes adopted with a p-n junction showed an improvement in the photovoltage. The measured OCP values are listed in Table S3. The trend of the $V_{\mathrm{ph}}$ values also correlates well with the onset potential of the GaN photoanodes.

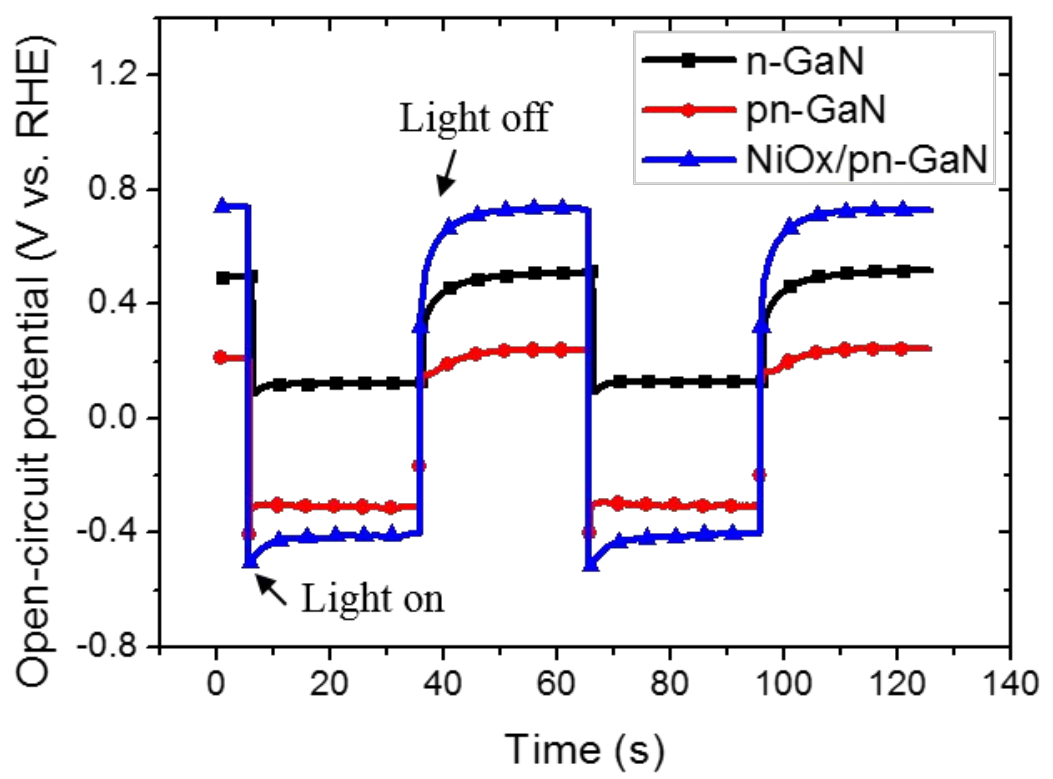

Figure S4. The OCP values of the $\mathrm{GaN}$ photoanodes under the dark and the illumination conditions before the stability test. 


\section{Supporting Information Section S5:}

The typical photocurrent-voltage responses of the $\mathrm{GaN}$ photoanodes in the $(0.1 \mathrm{M}$ $\left.\mathrm{Na}_{2} \mathrm{SO}_{4}\right)$ electrolyte and the $\left(0.1 \mathrm{M} \mathrm{Na}_{2} \mathrm{SO}_{4}+0.1 \mathrm{M} \mathrm{Na}_{2} \mathrm{SO}_{3}\right)$ electrolyte are shown in Figures S5a,b, respectively. The corresponding charge separation efficiency and interfacial charge transfer efficiency are shown in Figures S5c,d, respectively. The calculation as follow:

Incident photon-to-current conversion efficiency:

$I P C E=\eta_{\text {light }} \times \eta_{\text {sep }} \times \eta_{\text {transfer }}---(1)$

where $\eta_{\text {light }}, \eta_{\text {sep }}$, and $\eta_{\text {transfer }}$ represent the light-harvesting efficiency, the charge separation and transport efficiency, and the interfacial charge transfer efficiency, respectively.

Light-harvesting efficiency can be determined by integrating the diffuse reflectance spectra in Figure 6a and the standard AM1.5 G spectrum. We have the theoretical maximum photocurrent density $\left(\mathrm{J}_{\text {light }}\right)$ of our $\mathrm{GaN}$ photoelectrodes.

Assuming the $\eta_{\text {sep }}$ and the $\eta_{\text {transfer }}$ to $100 \%$,

$J_{\text {light }}=J_{\max } \times \eta_{\text {light }}---(1)$

$\mathrm{n}-\mathrm{GaN}: J_{\text {light }}=0.454 \mathrm{~mA} \mathrm{~cm}^{-2}$,

pn $-\mathrm{GaN}: J_{\text {light }}=0.463 \mathrm{~mA} \mathrm{~cm}^{-2}$,

$\mathrm{NiOx} / \mathrm{pn}-\mathrm{GaN}: J_{\text {light }}=0.465 \mathrm{~mA} \mathrm{~cm}^{-2}$.

where the theoretical maximum photocurrent density $\left(\mathrm{J}_{\max }\right)$ of the $\mathrm{GaN}(\mathrm{Eg}=3.4 \mathrm{eV})$ is estimated to be around $0.6 \mathrm{~mA} \mathrm{~cm}^{-2}$.

Now, denote the photocurrent in the $0.1 \mathrm{M} \mathrm{Na}_{2} \mathrm{SO}_{4}$ electrolyte and the $0.1 \mathrm{M} \mathrm{Na}_{2} \mathrm{SO}_{4}$ $+0.1 \mathrm{M} \mathrm{Na}_{2} \mathrm{SO}_{3}$ electrolyte as $\mathrm{J}_{\mathrm{a}}$ and $\mathrm{J}_{\mathrm{b}}$, respectively.

In the $0.1 \mathrm{M} \mathrm{Na}_{2} \mathrm{SO}_{4}$ electrolyte,

$J_{a}=\mathrm{J}_{\max } \times \eta_{\text {light }} \times \eta_{\text {sep }} \times \eta_{\text {transfer }}$

In general, the charge transfer efficiency can be considered almost $100 \%$ with the adding of the hole scavenger $\left(\mathrm{Na}_{2} \mathrm{SO}_{3}\right) .{ }^{1}$ Then, we have

$J_{b}=J_{\max } \times \eta_{\text {light }} \times \eta_{\text {sep }}$--- (3)

$\therefore \eta_{\text {transfer }}=\frac{(2)}{(3)}$ and $\eta_{\text {sep }}=\frac{(3)}{(1)}$

AM1.5 G spectrum can be found in the NERL website:

(https://www.nrel.gov/grid/solar-resource/renewable-resource-data.html) 

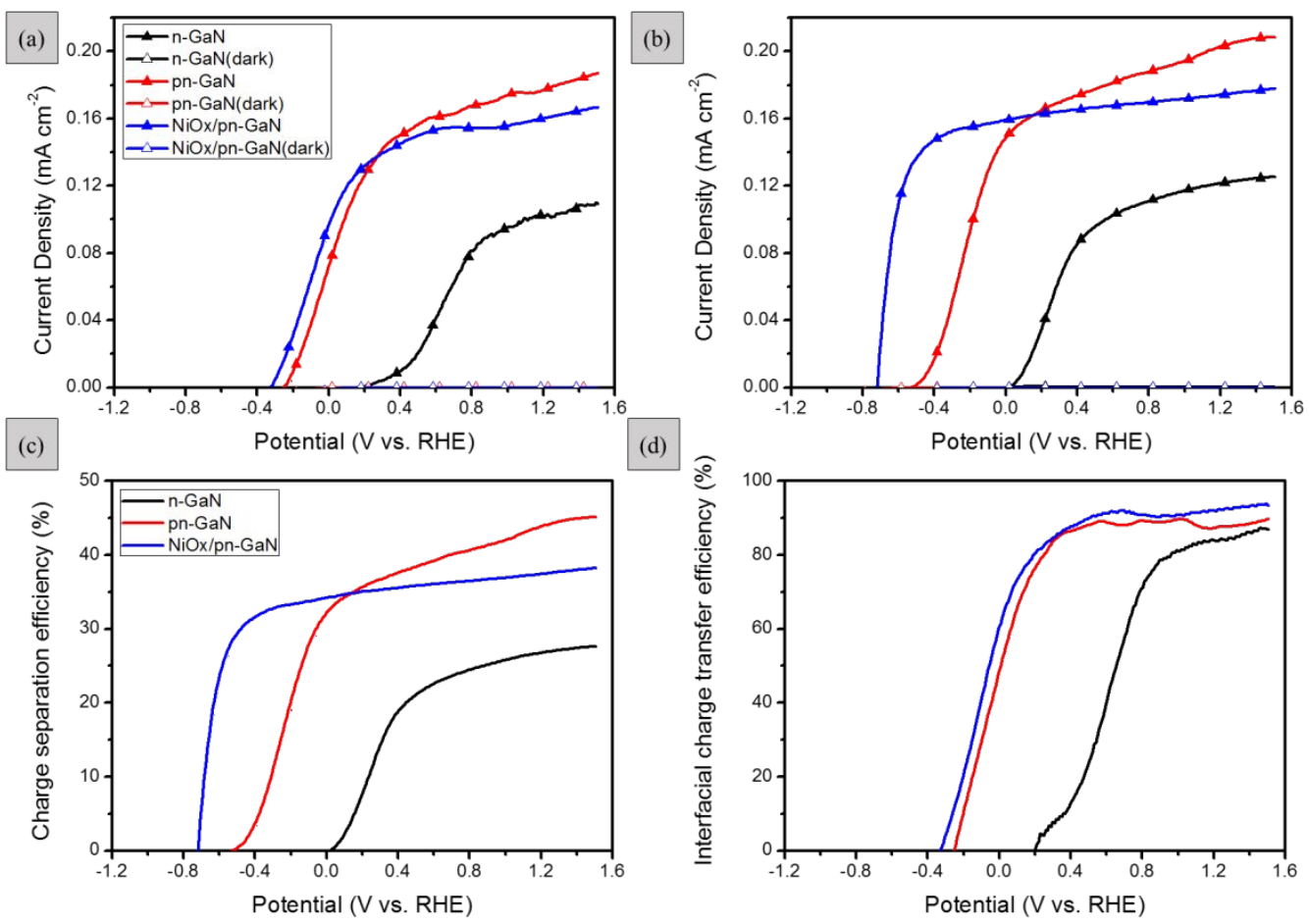

Figure S5. LSV scans of the $\mathrm{GaN}$ photoanodes in the (a) $0.1 \mathrm{M} \mathrm{Na}_{2} \mathrm{SO}_{4}$ electrolyte and the (b) $0.1 \mathrm{M} \mathrm{Na}_{2} \mathrm{SO}_{4}+0.1 \mathrm{M} \mathrm{Na}_{2} \mathrm{SO}_{3}$ electrolyte. (c) The corresponding charge separation efficiency and (d) the interfacial charge transfer efficiency of the GaN photoanodes. 


\section{Supporting Information Section S6:}

The LSV measurements shown in Figure S6 were performed in a 2-electrode configuration with a Pt-foil as the counter electrode. The photocurrent spikes were reduced significantly after the stability test. Along with the XPS results, indicating the $\mathrm{Ni}^{3+}$ species are more desirable for water oxidation. More importantly, our NiOx/pnGaN photoanodes showed a significant photocurrent at zero bias throughout the PEC reactions.

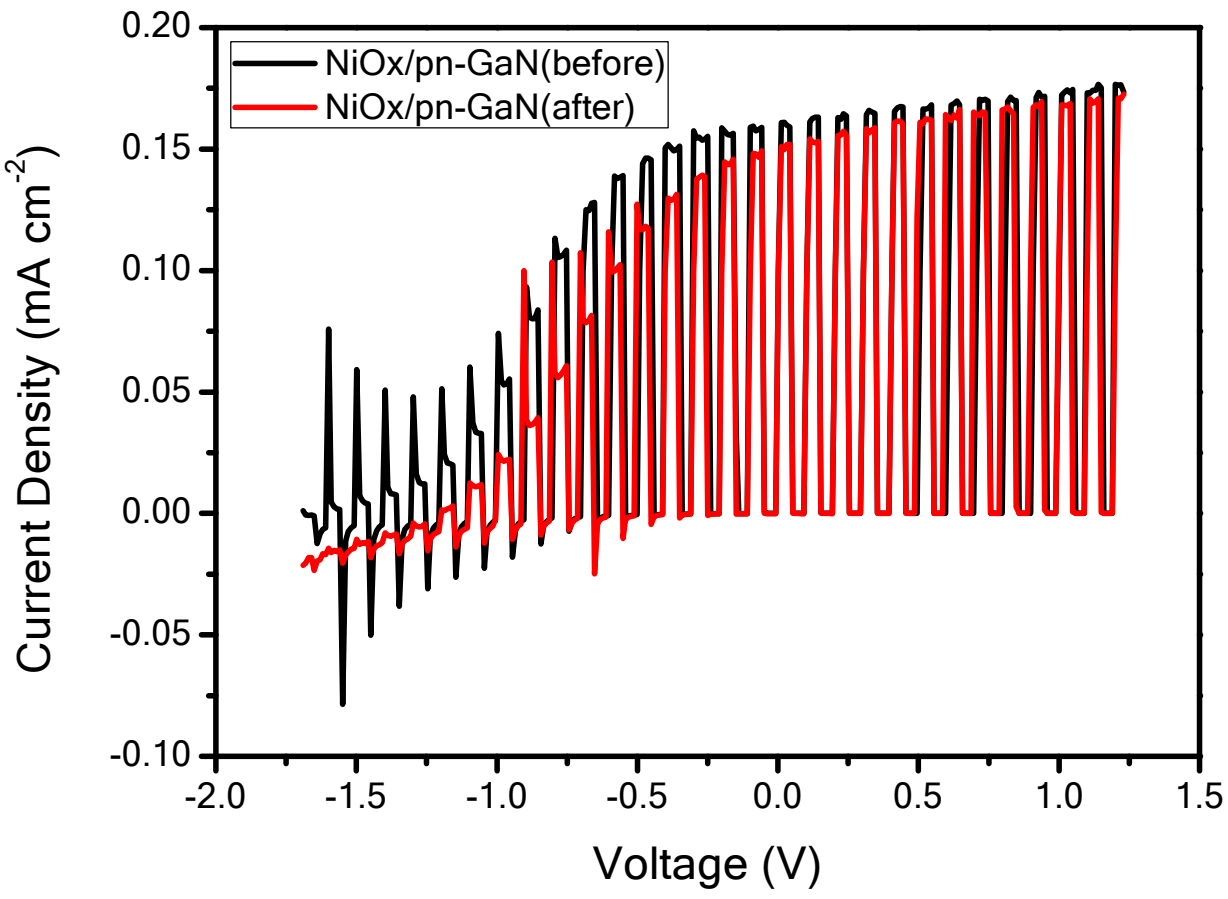

Figure S6. The LSV scans of the $\mathrm{NiO} x / \mathrm{pn}-\mathrm{GaN}$ photoanodes under a 2-electrode configuration just before and after the stability test. 


\section{Supporting Information Section S7:}

Figures S7a,b shows the equivalent circuit of the Nyquist plot used in this study. The s-model and the pn-model were used to fit the single-semicircle and the doublesemicircle features of the Nyquist plot, respectively. The solid lines shown in Figures $8 \mathrm{c}, \mathrm{d}$, and Figures S7c,d correspond to the impedance fitting results of the GaN photoanodes.

$\mathrm{R}_{\mathrm{s}}$ represents the series resistance of the system (including the resistance of the ohmic contact electrode, the wire connection, and the electrolyte). $\mathrm{R}_{\mathrm{ct}}$ and $\mathrm{CPE}_{\mathrm{ct}}$ correspond to the interfacial charge transfer resistance and the constant phase element of the semiconductor/electrolyte interface, respectively. $R_{p n}$ and $\mathrm{CPE}_{\mathrm{pn}}$ correspond to the $\mathrm{p}-\mathrm{n}$ junction resistance and the constant phase element of the $\mathrm{p}-\mathrm{GaN} / \mathrm{n}-\mathrm{GaN}$ interface, respectively.

In general, each semicircle in the Nyquist plot represents a particular junction interface. Before the stability test, the pn-GaN and the $\mathrm{NiO} x / \mathrm{pn}-\mathrm{GaN}$ showed a double-semicircle feature in Figure 8c,d. However, the Nyquist plot of the pn-GaN photoanodes showed only one semicircle left in Figure S7c,d after the stability test, suggesting the p-n junction interface was destroyed by the photocorrosion.

(a)

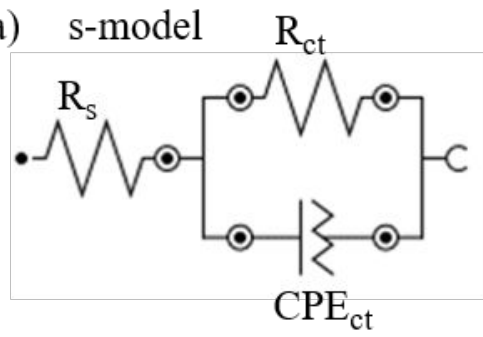

(c)

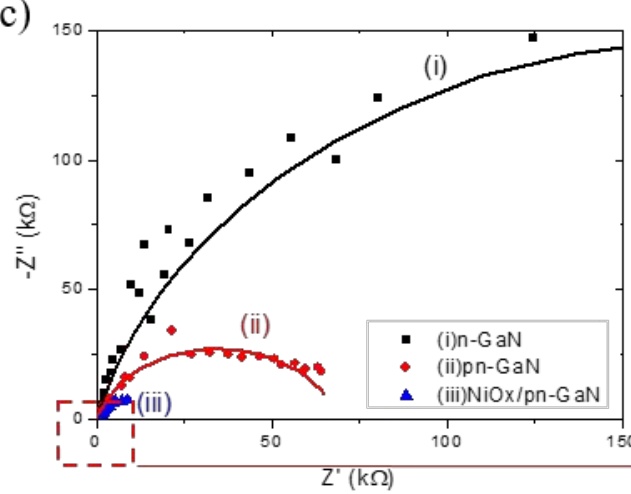

(b) pn-model
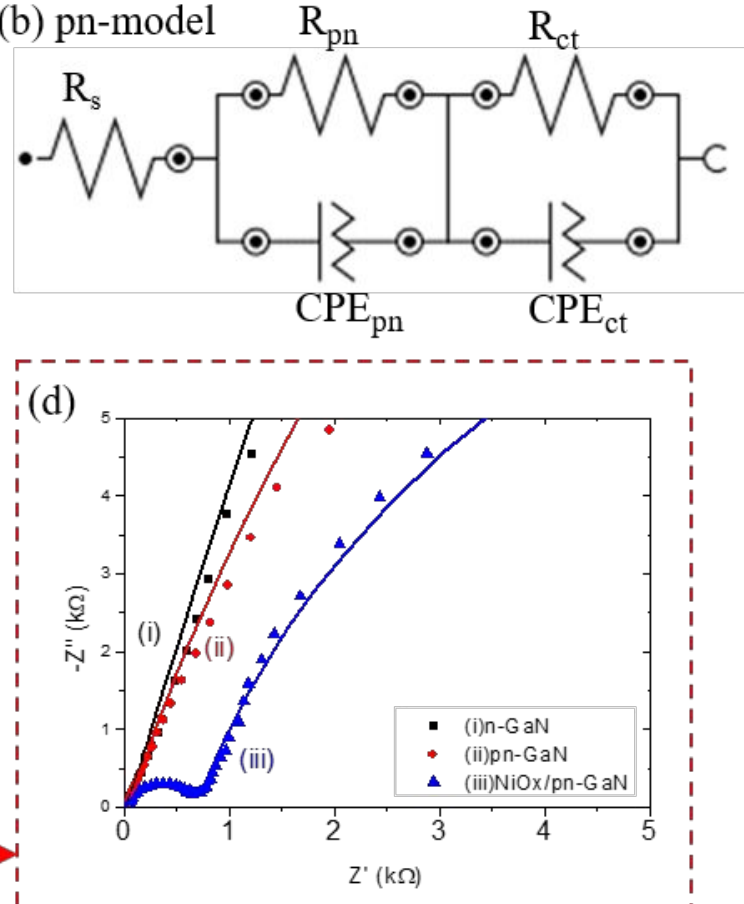

Figure S7. The equivalent circuit models of the (a) single-junction semiconductor (smodel), and the (b) p-n junction semiconductor (pn-model). (c) Nyquist plots of the GaN photoanodes at open-circuit potential under AM1.5 $\mathrm{G}$ illumination after the stability test. Solid lines represent the impedance fitting result. (d) Enlarged part of the Figure S7c. 
Supporting Information Section S8:
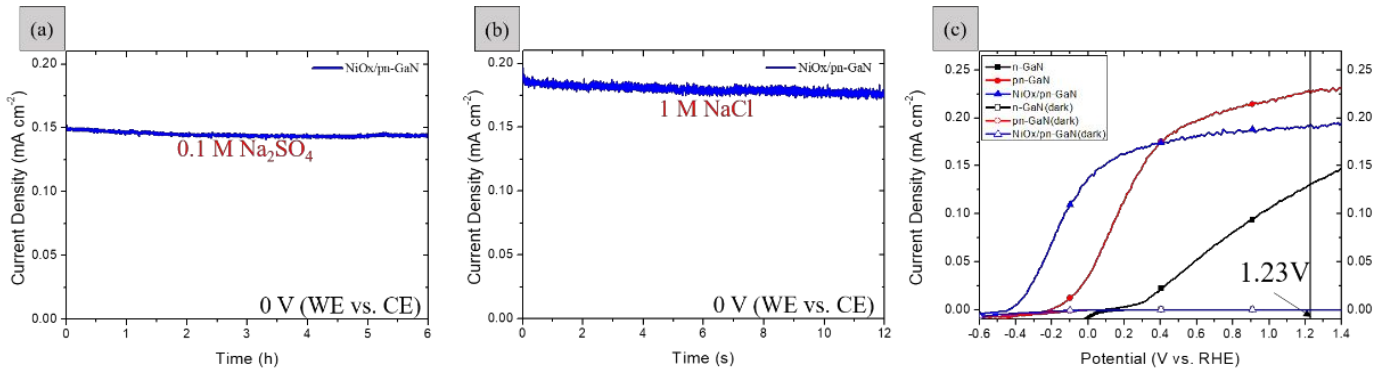

Figure S8. Current-time responses of the $\mathrm{NiO} x / \mathrm{pn}-\mathrm{GaN}$ photoanodes at $0 \mathrm{~V}$ bias under the two-electrode configuration in (a) $0.1 \mathrm{M} \mathrm{Na}_{2} \mathrm{SO}_{4}$, and (b) $1 \mathrm{M} \mathrm{NaCl}$. (c) LSV scans of the $\mathrm{GaN}$ photoanodes in $(1 \mathrm{M} \mathrm{NaCl})$ electrolyte under the $\mathrm{AM} 1.5 \mathrm{G}$ illumination. 


\section{References}

1. Chang, X.; Wang, T.; Zhang, P.; Zhang, J.; Li, A.; Gong, J., Enhanced Surface Reaction Kinetics and Charge Separation of $\mathrm{P}-\mathrm{N}$ Heterojunction Co3o4/Bivo4 Photoanodes. J Am Chem Soc 2015, 137, 8356-8359. 